\title{
Detection and Intervention Strategies by Primary Health Care Professionals in Suspected Elder Abuse
}

\author{
Deteção e Estratégias de Intervenção por Parte dos Profissionais dos Cuidados \\ de Saúde Primários na Suspeita de Abuso do Idoso
}

Mafalda FERREIRA $₫ 1$, César Lares dos SANTOS ${ }^{2,3}$, Duarte Nuno VIEIRA ${ }^{3}$

Acta Med Port 2015 Nov-Dec;28(6):687-694

\section{ABSTRACT}

Introduction: Primary health care professionals are in a privileged position to recognize and manage cases of suspected elder abuse. The purpose of this study was to provide some insight of these professionals' views and knowledge on this subject.

Material and Methods: A questionnaire was elaborated and sent to physicians and nursing staff practicing in 12 different health care units in Coimbra. The data collected included parameters related to demography, perception of abuse and management strategies, personal experience and training on this subject.

Results: The global response rate was $67.9 \%$ corresponding to 127 validated questionnaires. From the results found, we highlight the following: there was a significant contact between these professionals and older people; most (64.6\%) considered the abuse as more prevalent in the familiar context and $32.3 \%$ signed negligence as the most common type; the majority of professionals considered themselves as useful (97.6\%); the uncertainty in the diagnosis was one of the most important causes for non-reporting; there were doubts concerning mandatory report of abuse to judicial authorities. It was also found that $87.4 \%$ of the respondents stated they would feel more comfortable having formal protocol to handle these cases and this subject was not included in the training curriculum of $70.9 \%$ of the respondents.

Discussion: The significant contact between older population and health care professionals allows for an early diagnose and intervention. The professionals showed knowledge in accordance to some studies, namely, as to the context and prevalence of abuse. Doubts as to the best way to manage these cases could be solved by implementing protocols and by specific training, which is a fundamental cornerstone for preparing professionals to deal with these kind of cases.

Conclusion: Health care professionals seemed to be aware of the relevance of elder abuse, as well as the importance of their role in preventing and diagnosing these abuses. However, a more extensive approach on this subject during clinical training and the definition of general clinical guidelines are important to increase the professionals' confidence in managing suspected cases.

Keywords: Elder Abuse; Mistreatment; Primary Health Care; Portugal.

\section{RESUMO}

Introdução: Os profissionais dos cuidados de saúde primários encontram-se numa posição privilegiada para identificarem e orientarem casos de maus-tratos de idosos. Este estudo investigou o enquadramento destes profissionais nesta matéria.

Material e Métodos: Elaborou-se um questionário posteriormente aplicado a médicos e enfermeiros de 12 Unidades de Saúde de Coimbra. Estudaram-se parâmetros relacionados com aspetos demográficos, perceção do abuso e estratégias de atuação, experiência pessoal e formação nesta área.

Resultados: A taxa global de resposta foi de $67,9 \%$ com 127 questionários validados. Dos resultados obtidos destacam-se seguintes: verificou-se um contacto substancial entre os profissionais e a população idosa; a maioria dos profissionais $(64,6 \%)$ consideram o abuso mais prevalente em contexto familiar e 32,3\% indicaram a negligência como a forma mais frequente; $97,6 \%$ dos profissionais considera que tem um papel importante na deteção de casos de abuso; a incerteza no diagnóstico foi um dos principais fatores limitadores da denúncia; verificou-se incerteza a obrigatoriedade de reportar os casos às autoridades judiciais. Ainda se constatou que $87,4 \%$ destes profissionais se sentiriam mais confortáveis com protocolos de atuação e que esta problemática não havia sido abordada na sua formação básica em $70,9 \%$ dos casos.

Discussão: O contato significativo entre a população idosa e os profissionais de saúde propicia o diagnóstico e intervenção precoces. Os profissionais revelaram conhecimentos sobre o tema em linha com os indicados por alguns estudos, nomeadamente, sobre 0 contexto e prevalência do abuso. A subsistência de dúvidas relativamente à melhor forma para gerir estes casos e conciliar as diferentes perspetivas poderia ser colmatado, na opinião veiculada pelos próprios, pela definição de protocolos de atuação e a formação específica deverá ser considerada como um dos pilares fundamentais para preparar adequadamente os profissionais para lidar com este tipo de situações.

Conclusão: Existe uma consciencialização dos profissionais de saúde sobre a relevância do problema e sobre o papel que podem desempenhar na prevenção e diagnóstico do abuso. A abordagem do tema durante a sua formação associada ao desenvolvimento de normas de orientação clínica daria uma maior segurança aos profissionais na gestão destes casos.

Palavras-chave: Abuso de idosos; Maus Tratos; Cuidados Primários; Portugal.

\footnotetext{
1. Faculdade de Medicina. Universidade de Coimbra. Coimbra. Portugal.

2. Instituto Nacional de Medicina Legal e Ciências Forenses, IP. Gabinete Médico-legal e Forense Médio Tejo. Tomar. Portugal.

3. Centro de Ciências Forenses. Faculdade de Medicina. Universidade de Coimbra. Coimbra. Portugal.

$\bowtie$ Autor correspondente: Mafalda Ferreira. mafalda.alvesferreira@gmail.com

Recebido: 12 de Junho de 2015 - Aceite: 07 de Outubro de 2015 | Copyright @ Ordem dos Médicos 2015
} 


\section{INTRODUCTION}

Elder abuse is currently highlighted as a public health problem in our society, as the aging of the population becomes more evident. ${ }^{1,2}$

The UN estimates that the rate of the world's population aged 60 years or older has evolved from $8 \%$ in 1950 to $12 \%$ in 2013 , and an exponential increase up to $21 \%$ by 2050 is expected. ${ }^{3}$

The Portuguese old-age-dependency ratio (ratio between the number of older people and the number of working age people) has increased to $29.4 \%$ in 2013 , above the European average. ${ }^{4}$

The World Health Organization (WHO) worries that, in this context, there will be more cases of elder maltreatment caused by the breaking of family ties and poorer social services. ${ }^{2,5}$ Simultaneously, aging will imply more physical, emotional and social vulnerability of elders, as elders they become victims of their own fragility. 2,6

The WHO's adopted elder abuse definition is 'Elder abuse is a single or repeated act or lack of appropriate action, occurring within any relationship where there is an expectation of trust which causes harm or distress to an older person. ${ }^{1,7}$ Elder abuse can be physical, emotional, sexual, financial or neglect (intentional or not), and can occur isolated or in association. , $^{1,5}$

The assessment of the actual prevalence rate has proven to be a challenge, but some international studies estimate it ranging between $1 \%$ and $35 \%$ depending on definitions, survey or sample methods. ${ }^{1}$ Several authors claim these values are only the 'tip of the iceberg' and some believe that more than $80 \%$ of cases aren't detected. ${ }^{1}$

Available literature on this topic is scarce, more so in Portugal. ${ }^{2}$ Nevertheless, relevant studies have been published, particularly the recent project 'Envelhecimento e violência' estimated that $12.3 \%$ of portuguese over 60 years old have been victims of violence at least once in the 12 month period, prior to the study. ${ }^{8}$

In 1975, Baker A brought this issue to the attention of the medical community, referring to it as granny-battering and pointing out the need for professionals to become more conscious. ${ }^{9,10}$ Since then, several authors have been highlighting the significant role health professionals should have in this area. ${ }^{1}$ Kahan and Paris ${ }^{11}$ declared that "health professionals may be the only people in the victim's life with the ability to recognize the situation and provide assistance.'

Therefore, health services are a fertile ground for the implementation of evaluation routines, detection and prevention of abuse. ${ }^{6,10}$ However, abuse cases continue to be underdiagnosed and underreported. The intervention should not be limited to the identification of victims but also initiate an assistance program, with the cooperation of medical, legal and social entities. , $^{1,10}$

Despite the existing focus on the role of health professionals, especially in primary health care, few studies have been published regarding their approach to this issue, namely, their specific training and the self-perception of the potentials and limitations of their role in the assisted community.

In fact, the authors could not find any national studies for this purpose, which increased the motivation to carry out this study.

\section{MATERIAL AND METHODS}

The authors performed a literature survey, using PubMed and generic search engines, aimed to find scientific work on elder abuse, the role of health professionals and questionnaires elaborated in this context, through keywords such as 'elder', 'abuse', 'mistreatment', 'health', 'professionals' and 'questionnaire'.

After selecting and analyzing the literature, a questionnaire was developed with the most relevant elements for Primary Health Care (PHC) professionals. The questionnaire was limited to two pages in order to guaranty a better response rate.

The questionnaire was divided into five sections: I Socio-demographic characteristics; Il- Perception of abuse; III - Perception of intervention techniques; IV - Personal experience and V- Education and training on the subject, in a total of 27 questions. It also included an open area for participants' comments and remarks.

Due to the unfeasibility to list all signs/symptoms of abuse and as it was not found any addressing their relative diagnostic value, in section II, fourteen situations were selected, representative of the five types of abuse considered by $\mathrm{WHO}$, for the participants to value their diagnostic relevance on a crescent five-level Likert-type item. Indications were given to evaluate each item individually. For further analysis, results were grouped dichotomically as: Not Relevant/Relevant and Not Pathognomonic/ Pathognomonic.

Similarly, in section III, from the reasons pointed out in the literature as relevant to underreporting of suspicious cases, ten were selected to be evaluated on a three-level Likert-type item. To enhance the discriminatory power, the option 'I do not agree / nor disagree' was removed from later analyses.

Health professionals, not included in the final sample, were asked to complete the questionnaire and report any doubts or ambiguity in the phrasing of the questions.

The questionnaire was then applied to general physicians (including junior doctors in this specialty) and nurses from 12 Primary Health Care Units of Coimbra integrating the ACeS (Group of Health Units) do Baixo Mondego during the period of October to December 2014. The choice of location was related to geographical accessibility. Filling the questionnaire was anonymous and voluntary.

A total of 129 were completed, while 2 were excluded due to lack of response to a significant number of questions. Consequently, the final sample included 127 questionnaires.

Descriptive and inferential statistical analysis of the data was performed, using $\chi^{2}$-square test and Fisher's Exact Test, and a significance level of $p<0.05$ was established. The software tools used were the Excel 2007 and SPSS v. 
20. The lack of answers or invalid responses (eg. multiple answers to single response questions) were considered missing values and removed from the analysis. The Likert-type scales were treated as ordinal variables. In the following text, unless otherwise stated, 'physicians' includes general physicians and younger doctors.

This questionnaire was approved by the ARSC Ethics Committee - Administração Regional de Saúde do Centro (Regional Health Administration of the Centre), by the ACeS do Baixo Mondego and the coordinators of USFs - Unidades de Saúde Familiar (Family Health Units) participants.

\section{RESULTS}

The questionnaire was distributed to 12 Primary Healthcare units in Coimbra, covering a population of approximately 150000 users, featuring 190 health professionals (107 doctors and 83 nurses).

There was a $67.9 \%$ global response rate and a final valid sample of 127 questionnaires, after the exclusion of 2 questionnaires.

\section{Sociodemographic characteristics}

The sociodemographic characteristics are shown in Table 1.

\section{Perception of abuse}

Regarding the abuse prevalence estimate in Portugal, the mode corresponded to option ' $5-10 \%$ of elder population' and more than $50 \%$ of professionals estimated it in $1-10 \%$. In 13 cases $(10.2 \%)$, the prevalence was estimated as being higher than $20 \%$.

The most common context of abuse, in $64.6 \%$ ( $n=$ 82) of the answers, was familiar, which is significant, even considering $21.3 \%(n=27)$ of missing or invalid responses. As for the most prevalent type of abuse, 32.3\% of respondents selected neglect followed by emotional abuse $(22.1 \%)$. The financial $(7.1 \%)$ and physical abuse $(4.7 \%)$ were chosen less frequently and sexual abuse never selected as the most frequent form of abuse. No statistically significant differences in the answers were found related to gender, age, occupancy or years of experience in clinical practice.

As for the recognition of signs / symptoms of abuse and their valorization when considered individually, we calculated the variation $(\Delta)$ between 'Relevant' and 'Not Relevant' groups.

The results are displayed in Table 2.

It should be highlighted that two situations have been most commonly identified as pathognomonic: lesions in different development stages $(31.5 \%)$ and signals of physical constriction (30.7\%).

There were also the following statistically significant findings: participants aged 50 - 59 years tend to not give importance to the presence of STDs (Sexual Transmitted Diseases); professionals with 1 to 5 years of clinical practice tend to not give relevance to pressure ulcers, younger physicians and subjects aged $<30$ years tend to find
Table 1 - Socio-demographic characteristics of the study participants $($ Total $=127)$

\begin{tabular}{|c|c|c|}
\hline Demographic characteristics & $\mathbf{n}$ & $\%$ \\
\hline \multicolumn{3}{|l|}{ Gender } \\
\hline Male & 24 & $18.9 \%$ \\
\hline Female & 102 & $80.3 \%$ \\
\hline Lack of response & 1 & $0.8 \%$ \\
\hline \multicolumn{3}{|l|}{ Age } \\
\hline$<30$ & 21 & $16.5 \%$ \\
\hline $30-39$ & 23 & $18.1 \%$ \\
\hline $40-49$ & 23 & $18.1 \%$ \\
\hline $50-59$ & 33 & $26.0 \%$ \\
\hline$\geq 60$ & 20 & $15.8 \%$ \\
\hline Lack of response & 7 & $5.5 \%$ \\
\hline \multicolumn{3}{|l|}{ Profession } \\
\hline Nurse & 55 & $43.3 \%$ \\
\hline General physician & 46 & $36.2 \%$ \\
\hline Younger physician & 25 & $19.7 \%$ \\
\hline Lack of response & 1 & $0.8 \%$ \\
\hline \multicolumn{3}{|l|}{ Years of clinical practice } \\
\hline$<1$ & 2 & $1.6 \%$ \\
\hline $1-5$ & 24 & $18.9 \%$ \\
\hline $6-10$ & 5 & $3.9 \%$ \\
\hline $11-15$ & 11 & $8.7 \%$ \\
\hline$>15$ & 84 & $66.1 \%$ \\
\hline Lack of response & 1 & $0.8 \%$ \\
\hline \multicolumn{3}{|l|}{ Type of health unit } \\
\hline UCSP & 61 & $48.0 \%$ \\
\hline USF & 66 & $52.0 \%$ \\
\hline \multicolumn{3}{|l|}{ Population assisted } \\
\hline Rural & 5 & $3.9 \%$ \\
\hline Urban & 46 & $36.2 \%$ \\
\hline Mixed & 75 & $59.1 \%$ \\
\hline Invalid response & 1 & $0.8 \%$ \\
\hline \multicolumn{3}{|l|}{ Number of assisted population } \\
\hline$<1500$ & 13 & $10.2 \%$ \\
\hline $1500-1900$ & 92 & $72.4 \%$ \\
\hline$>1900$ & 22 & $17.3 \%$ \\
\hline \multicolumn{3}{|c|}{ Percentage of elderly in the clinical file } \\
\hline$<25 \%$ & 25 & $19.7 \%$ \\
\hline $25-50 \%$ & 47 & $37.0 \%$ \\
\hline $59-75 \%$ & 42 & $33.1 \%$ \\
\hline$>75 \%$ & 8 & $6.3 \%$ \\
\hline Lack of response & 5 & $3.9 \%$ \\
\hline \multicolumn{3}{|l|}{ Home Visiting } \\
\hline Yes & 118 & $92.9 \%$ \\
\hline No & 8 & $6.3 \%$ \\
\hline Lack of response & 1 & $0.8 \%$ \\
\hline
\end{tabular}

relevant the older person being left alone by the caregiver most of the day. It should be noted that it was requested the valorization symptoms/signs individually.

There were no statistically differences in gender, age, occupancy or years of experience in clinical practice and the labeling of a situation as 'pathognomonic'. 
Table 2 - Variation $(\Delta)$, in descending order, between 'Relevant' and 'Not Relevant' groups on the question about signs / symptoms of abuse and their valorization

Variation $(\Delta)$ between

'Relevant' and 'Not Relevant'
Depressive symptoms with emotional ambivalence towards the caregiver

$94.4 \%$

$91.2 \%$

Signs of deficient personal hygiene

$85.8 \%$

Evidence of over or under medication

Irregular medical care characterized by missing the scheduled appointments

Concern about money management by the caregiver

$76.3 \%$

Lesions in different development stages

Caregiver leaves the elderly alone most of the day

$74.1 \%$

Absence of dentures, glasses or crutches when necessary

$66.8 \%$

Signs of physical constriction

$66.2 \%$

Dressed inappropriately

$59.8 \%$

Presence of bedsore ulcers

$45.6 \%$

Anogenital complaints

$41.7 \%$

Unexpected change in the will

$31.5 \%$

\section{Perception of intervention techniques}

When confronted with the statement that elder abuse is a problem, particularly, of a judicial / social nature rather than a health problem, 60 professionals $(47.2 \%)$ considered it not to be the case, while $48(37.8 \%)$ view it as mostly a judicial / social matter and $11.8 \%$ neither agreed nor disagreed. A statistically significant pattern, related to age, was observed: older participants tend to regard more frequently the abuse as a matter of judicial / social nature.

As for their self-perception of their usefulness in the diagnosis of abuse, the majority of professionals considered themselves as useful $(97.6 \% ; n=124)$, while 3 didn't respond and 2 neither agreed nor disagreed. A significant percentage of participants $(79.5 \% ; n=101)$ stated professionals should take responsibility in the diagnosis and only 9 opposed this idea.

In what concerns case reporting, 63.8\% ( $n=81)$ of participants considered mandatory to report to the authorities when facing a suspicious situation, a percentage that increases slightly to $70.1 \%(n=89)$ in those cases where the victim reports experiencing abuse. It should be noted that $36(28.4 \%)$ respondents said they did not know whether they were obliged to report when facing a suspicious situation and $34(26.8 \%)$ did not know whether they were required to do so after the older person reported a situation of abuse.
To report the situation, most professionals $(74.0 \%$; $\mathrm{n}=94)$ consider only the Social Services and $12(9.5 \%)$ the Judicial Authorities. In 21 cases (16.6\%), the report would be made to two or more entities; the most frequent combination was Social Services / Judicial Authorities. In 4 cases, the Portuguese Association for Victim Support (APAV) was indicated.

Appreciation the proposed reasons that justify the nonfilling of a complaint, following the calculation of the variation $(\Delta)$ between the responses 'Agree' and 'Disagree'.

The results to this question are shown in table 3 , in descending order of variation $(\Delta)$.

It is worth emphasizing that only two situations raised a clear agreement $(\Delta>20 \%)$ : the uncertainty of the diagnosis and the difficulty in differentiating whether the complaints of the older person (which constitute abuse) correspond to reality or are just a distorted perception of it).

For each of the proposed situations, there were no significant differences related gender, age, profession or years of experience.

The questionnaire also allowed the respondents to mention any other reasons it could make them feel less prone to reporting, but none was mentioned.

Regarding the importance of a protocol, most professionals $(87.4 \% ; n=111)$ reported that they would be more comfortable if one was implemented, while 7 (5.5\%) 
revealed that they prefer to handle case by case and 5 (3.9\%) reported using a protocol (not specified).

Also significant was the response of $116(91.3 \%)$ of the participants that considered useful the existence of a specific non-judiciary entity to whom they could report cases.

\section{Personal experience}

Concerning their clinical practice, 61.4\% $(n=78)$ of professionals said that they had already suspected of some cases of abuse. Of these, $55(70.5 \%)$ counted up to 5 suspected cases, $10(12.9 \%)$ counted more than 5 cases and 8 mentioned an unspecified number of situations. In 5 $(6.4 \%)$ cases a response was not indicated. A significant difference between the profession and years of clinical practice was found, as younger doctors and professionals with fewer years of clinical exercise reported fewer suspected cases. When asked about the suspicion of abuse cases in the last twelve months, 24 (30.8\%) answered affirmatively and $50(64.1 \%)$ negatively.

Of the participants whom indicated that they had suspected cases throughout their career ( $n=65)$, the majority $(83.3 \%)$ said to have reported the situation and, in 2 cases, the question wasn't answered. The majority of those who report it $(80.0 \%)$ referred the case to the Social Service. A very small number of cases referred directly to the public prosecutor offices or police authorities. There was also who talked to the family or the manager of the home and a case that the situation was already monitored by the police.

\section{Education and training on the subject}

This issue was not addressed in the basic training of $90(70.9 \%)$ surveyed professionals and, of the $36(28.4 \%)$ who reported having had training, 34 (94.4\%) believe a more extensive approach on the subject would have been important. A statistically difference was found related to age, where $95 \%$ of professionals over 60 years old indicated that they had no specific training. However, it is also noteworthy that $57.1 \%$ of professionals under 30 indicated they had not any basic training either.

More than half of the surveyed professionals $(63.0 \%$; $\mathrm{n}=80$ ) reported never having attended training activities focused on this issue during their careers. It stands out, however, that a significant majority $(96.9 \% ; n=123)$ considered additional training relevant or very relevant to their usual clinical practice, with only $4(3.2 \%)$ respondents considering it as of little relevance.

Table 3 - Variation $(\Delta)$, in descending order, between the responses 'Agree' and 'Disagree' to the question about the reasons that justify the non-filling of a complaint

Variation $(\Delta)$ between 'Agree' and 'Disagree'

Difficulty in differentiating whether the complaints of the elderly (which constitute abuse) correspond to reality or are just a distorted perception of it

The professional fears the aggressor might pursue judicial action against him/her if abuse is not proven in a court of law 


\section{DISCUSSION}

The activity area of the Health Units involved in the study, covers a population of about 150000 users where most professionals handle between 1500 to 1900 users. More than three quarters of these professionals estimated that at least $25 \%$ of their users are older individuals. It is noted that there is a significant contact with the older population, which puts these professionals in an ideal position to access the older individuals and detect signs of potential abuse..$^{6,12-14}$ In addition, $92.2 \%$ of health professionals say they perform home visits, which gives them a unique perspective of the older person's family environment and their interaction with caregivers. ${ }^{15}$ This extended contact with possible victims of abuse, allows for the development of awareness for the older individual and caregivers aiming to control and diminish risk factors (primary prevention), and for an early identification of signs / symptoms of abuse (secondary prevention)..$^{15-17}$ In fact, in line with the contemporary perspective advocated by the $\mathrm{WHO}$, violence should be seen as a serious public health problem. ${ }^{1,2}$ Thus, it was important to find that $47.2 \%$ of professionals considered violence as a health problem and $37.8 \%$ as a judicial / social issue. Thus, given the number of invalid responses and absence of response, we can't establish a clear trend in either direction. However, almost all respondents $(97.6 \%)$ recognized the usefulness of health professionals in the diagnostic process, although only $79.5 \%$ assume they have a specific responsibility to do so.

In the field of perception of the prevalence of abuse, it was found that most professionals recognize this problem to be relatively frequent in Portugal. In $67 \%(n=85)$ of cases this prevalence was estimated to be more than $5 \%$, and $19(15 \%)$ considered it to be within the range of $10 \%-15 \%$, which is what best fits the $12.3 \%$ estimated in the project 'Envelhecimento e violência'. ${ }^{8}$ It stands out the $10.2 \%$ of cases $(n=13)$, in which the prevalence was estimated to be over $20 \%$. It is important to notice that international studies have not been conclusive, showing discrepancies in prevalence estimates, some reporting values as high as $35 \%{ }^{1}$

It was also found that more than half of the participants $(64.6 \%)$ believe that abuse often arises in the family context and $32.3 \%$ indicate neglect as the most practiced form of abuse, followed by emotional violence $(22.1 \%)$. These results are in accordance with some published studies. ${ }^{13,18}$ However, these results contrast with other studies, particularly with the project 'Envelhecimento e violência'8 that indicated financial and psychological violence as the greatest forms of abuse in the studied population, and neglect as the less frequent along with sexual violence.

On what signs/symptoms are concerned, for each of the proposed items, there were always respondents that ascribed the meaning of 'pathognomonic', and the most common were the observation of lesions in different developmental stages and the presence of physical constriction marks. The diagnosis of abuse is complex ${ }^{12}$ and requires the association of various signs and symptoms, some of which may be more important for professionals because they are perceived as being more frequently linked to abuse. A correct evaluation involves establishing differential diagnoses, in which should be considered the physiological changes of aging that could be confused with signs of abuse ${ }^{5,19}$ Also worth noting is the essential role of clinical interviews for the diagnosis. It is advised to carry out a series of questions during the interview, in a private conversation with the possible victim avoiding the presence of the supposed abuser ${ }^{16,19,20}$ for an early identification of abuse, as well as being aware of the physical signs, attitudes and emotional status of the older people. ${ }^{14,16,17}$ The victim's risk factors must also be determined, such as dementia or dependence for daily life activities, as well as risk factors associated with the caregivers themselves, like as stress, mental illness, alcoholism, economic difficulties amongst others. ${ }^{19,21}$

On the management of suspected abuse cases, $28.4 \%$ of respondents report not to know if they are obliged to report their suspicions to the judicial authorities and $26.8 \%$ do not know if, when faced with reports of abusive behavior, they are required to file a complaint.

The uncertainty about the obligation to report cases to judicial authorities is one of many factors of non-reporting, such as the lack of absolute certainty of the presence of abuse and uncertainty about whether the complaints of the older individuals correspond to reality or are just a distorted perception of the same. These last two aspects are in line with those found in other studies ${ }^{18,20}$ that support the idea that there is a shortfall in the training leading to diagnostic uncertainty and fear of making mistakes when reporting the complaint.

It must be recognized that the exercise of care activities performed by doctors and nurses carry certain particularities, such as, the professional secrecy, that can raise questions of how to act. However, it should be noted that articles 52 and 53 of the Portuguese Medical Association Code of Ethics ${ }^{22}$ explicitly indicate that a physician should use particular care for the minor, the older people or the disabled, especially when he thinks that the family or other caregivers are not capable or careful enough to care for their health or ensure their well-being. When he finds that they are victims of abuse, mistreatment or harassment, should take appropriate measures to protect them, including alerting the competent authorities, interpreting the value of professional secrecy. Reading the Portuguese Nurses' Code of Ethics, the interpretation seems similar, from the conjunction of article $81 \mathrm{c}$ ) to article $85, \mathrm{c}){ }^{23}$

Although this problem is considered by many authors as rarely reported by health professionals, and despite the fact that they occupy a privileged position to do so, ${ }^{10,20,24,25}$ the present study showed a good relationship between the cases in which there was suspicion and reporting. Indeed, of the $78(61.4 \%)$ participants who mentioned to have suspected of at least one event of abuse, $83.3 \%$ reported the situation.

A question that can be raised in this context is what can be understood by the proper 'authorities' to deal with this 
situation. Within the meaning of article 242 of the Portuguese Criminal Procedure Code $^{26}$ the reporting is mandatory for employees in respect to crimes that are known in the course of their duties and the information should be given to the judicial authorities. It is worth noting, that this article is not explicit of any time limit for the formulation of the complaint, allowing some flexibility in the course of action. This interpretation is stated in a document of the General Health Directorate (Direção Geral de Saúde) containing guidelines for abuse management on children and young people, establishing various levels of action, in which they emphasize the health services as being the front line, supported by Child \&Youth at Risk Support Centers, and in some cases the Child \& Youth Protection Commission (CPCJ) and, if necessary, appeal for judicial intervention. ${ }^{27}$ However, when answering the questions 'In case of suspicion and if you decided to report the situation to which entities would you call?' and 'In the suspicion of abuse have you ever reported the situation to other services?' it was found that only in a few cases legal authorities are considered as an option, being the preferred choice the Social Services.

Underlying this paradigm, some discomfort/reluctance was empirically recognized in professionals about coming in contact with the judicial environment. Other possible explanations are related to ease of access to social services and also the importance of maintaining of the trust relationship between the professionals, the older person and their families. In this sense, solutions that, apparently, better protect the interests of the victims while ensuring their autonomy, ${ }^{11,14,15}$ are preferable to others that result in the stigmatization that comes with judicial intervention, reducing the risk of breach of trust between professionals and family (a relationship that can help in restructuring the family).

On a more thorough reflection of the difficulties currently experienced by health professionals in deciding the best strategies that allow a balance between the interests of the patient, the professional obligations and the legal duties, it should be noted that $87.4 \%$ of respondents said they would feel more comfortable if there were defined action protocols and $91.3 \%$ considered it would be useful if there was a nonjudicial entity to whom report cases.

Clarification of the methodology to be applied in the management of these cases is necessary, perhaps in the form of clinical guidelines, already implement for abuse in other setting (child abuse), eventually containing some screening criteria to be applied in the older individual's routine observation.

Finally, concerning the topic of health professionals training, it was found that the subject of elder abuse was not addressed in $70.9 \%$ of cases, which is, in our view, an important lack in professional education. And, although a significant number of professionals without specific basic training in this area is over the age of 60 , which is understandable given that the issue of elder abuse has gained more visibility in the past two decades, it is far more worrisome that more than half of professionals aged under 30 years old have indicated that their basic training did not include this topic.

It should be highlighted that there are authors defending that it is more important to train and educate professionals about this matter in order to create awareness amongst them, than to design algorithms and screening methods. ${ }^{19}$ In fact, the effectiveness of the screening instruments already published, is yet to be supported by scientific evidence. . $^{8,10,14,16}$

It should be recognized that this study has some limitations. In order to generalize the results, it would be necessary to apply this questionnaire, or a similar one, in other health units in order to obtain a more significant and representative sample of the national scenario. On the other hand, the purpose of ensuring a greater response rate by elaborating a two page-questionnaire limited the number and type of questions, thus, precluding a more comprehensive approach to issues like the perception of professionals, their knowledge about signs that suggest abuse and the methods of suspicion management and making it impossible to fully compare this study with other previous studies.

Nonetheless, the authors believe that this study is relevant to reveal, in a general perspective, how this issue is perceived by $\mathrm{PHC}$ professional, a subject still not profoundly studied, namely at a national level.

\section{CONCLUSION}

Increasing health professionals' awareness and training on elder abuse, particularly those integrated into primary health care, is of utterly importance. Such relevance is even greater when recalling that older people most likely won't look for help and it is up to health professional to detect early warning signs in order to find possible victims.

In this study, health professionals have expressed concern and awareness for this issue and already acknowledged the role they may play in the prevention and diagnosis of abuse. Therefore, it is now important to enhance technical skills in diagnosing and managing of such cases.

In this regard, it seems extremely valuable the development of a protocol (as there are for management of abuse in other contexts), that could standardize procedures at a national level and promote a multidisciplinary approach, encompassing health, justice, autonomy of the older individuals and family promotion aspects. Such measures would contribute to boost the confidence of professionals managing these cases.

\section{ACKNOWLEDGEMENTS}

The authors would like to appreciate the invaluable contribution of the Primary Care Units involved in this study, UCSP Cruz de Celas; UCSP Eiras; UCSP Fernão Magalhães; UCSP Norton de Matos; UCSP Santa Clara; UCSP São Martinho; USF Briosa; USF Celas Saúde; USF Cruz de Celas; USF Mondego; USF Rainha Santa Isabel; 
USF Topázio and the health care professionals who took some time of their busy schedules to participate.

\section{PROTECTION OF HUMANS AND ANIMALS}

Approved by the ARSC Ethics Committee Administração Regional de Saúde do Centro (Regional Health Administration of the Centre), by the ACeS do Baixo Mondego and the coordinators of USFs - Unidades de Saúde Familiar (Family Health Units) participants.

\section{REFERENCES}

1. World Health Organization. A global response to elder abuse and neglect: building primary health care capacity to deal with the problem worldwide: main report. Geneve: WHO; 2008.

2. Borralho $O$. Maus-tratos e negligência a pessoas idosas: identificação e caracterização de casos no serviço de urgência de um hospital central. Mestrado em Psicologia [Dissertação]. Coimbra: Universidade de Coimbra, Faculdade de Psicologia e de Ciências da Educação; 2010.

3. Department of Economic and Social Affairs, Population Division. World population ageing; 2013. New York: United Nations; 2012

4. Eurostat, the statistical office of the European Union. Old-agedependency. [Consultado 2014 Nov 22]. Disponível em: http://epp. eurostat.ec.europa.eu/tgm/table.do?tab=table\&init=1\&plugin=1\&langua ge $=$ en\&pcode $=$ tsdde 510

5. Collins K. Elder maltreatment. Arch Pathol Lab Med. 2006;130:1290-6.

6. Associação Portuguesa de Apoio à Vítima. Manual títono para o atendimento de pessoas idosas vítimas de crime e violência. Lisboa: APAV; 2010.

7. Santos AJ, Nicolau R, Fernandes A, Gil AP. Prevalência da violência contra as pessoas idosas. Sociologia, Problemas e Práticas. 2013;72:53-77.

8. Projeto Envelhecimento e Violência. Lisboa: Instituto Nacional de Saúde Doutor Ricardo Jorge; 2014.

9. Burston GR. Letter: granny-battering. Br Med J. 1975;3:592.

10. Perel-Levin S. WHO. Discussing screening for elder abuse at primary health care level. Geneve: WHO press; 2008.

11. Perez Carceles MD, Rubio L, Pereniguez JE, Perez-Flores D, Osuna E, Luna A. Suspicion of elder abuse in South Eastern Spain: the extent and risk fators. Arch Gerontolgeriatr. 2009;49:132-37.

12. Yaffe M, Tazkarji B. Understanding elder abuse in family practice. Can Fam Physician. 2012;58:1336-40.

13. McCreadie C, Bennett G, Gilthorpe M, Houghton G, Tinker A. Elder abuse: do general practitioners know or care? J R Soc Med. 2000;93:6771.

14. Costa I, Pimenta A, Brigas D, Santos L, Almeida S. Maus tratos nos

\section{DATA CONFIDENTIALITY}

The authors declare that the confidentiality of the patients was always maintained.

\section{CONFLICTS OF INTEREST}

The authors declare that there are no conflicts of interest.

\section{FUNDING SOURCES}

No subsidies or grants contributed to this work.

idosos: Abordagem nos cuidados de saúde primários. Rev Port Clin Geral. 2009;25:537-42.

15. Bernal A, Gutièrrez J. Malos tratos a personas mayores: guía de actuación. IMSERSO; 2005.

16. Fernández-Alonso $\mathrm{MC}$, Herrero-Velézquez $\mathrm{S}$. Maltrato en el anciano. Posibilidades de intervención desde la atención primaria (I). Aten Primaria. 2006;37:56-9.

17. Fernández-Alonso $\mathrm{MC}$, Herrero-Velézquez S. Maltrato en el anciano. Posibilidades de intervención desde la atención primaria (II). Aten Primaria. 2006;37:113-5.

18. Jones JS, Veenstra TR, Seamon JP, Krohmer J. Elder mistreatment: national survey of emergency physicians. Ann Emerg Med. 1997;30:473-

19. Lachs M, Pillemer K. Elder abuse. Lancet. 2004;364:1263-72.

20. Gorbien M, Eisenstein MA. Elder abuse and neglect: an overview. Clin Geriatr Med. 2005;279-92.

21. Levine J. Elder neglect and abuse: a primer for primary care physicians. Geriatrics. 2003:58:37-44.

22. Código Deontológico Médico. [consulted 2014 Nov 22]. Available from: https://www.ordemdosmedicos.pt.

23. Código Deontológico do Enfermeiro. [consulted 2014 Nov 22] Available from: http://www.enfermagem.edu.pt/images/stories/ CodigoDeontologico.pdf.

24. Kleinschmidt K. Elder abuse: a review. Ann Emerg Med. 1997;30:463 72.

25. Rodríguez M, Wallace S, Woolf N, Mangione C. Mandatory reporting of elder abuse: between a rock and a hard place. Ann Emerg Med. 2006;4:403-9

26. Código do Processo Penal. [Consulted 2014 Nov 22]. Available from: http://www.pgdlisboa.pt/leis/lei_mostra_estrutura. php?tabela=leis\&artigo id=\&nid=199\&nversao=\&tabela=leis\&so miolo=.

27. Direcção-Geral da Saúde. Maus tratos em crianças e jovens: Intervenção da saúde. Lisboa: Direcção-Geral da Saúde; 2008. 


\section{Detection and Intervention Strategies by Primary Health Care Professionals in Suspected Elder Abuse}

Acta Med Port 2015:28:687-694

Publicado pela Acta Médica Portuguesa, a Revista Científica da Ordem dos Médicos

Av. Almirante Gago Coutinho, 151

1749-084 Lisboa, Portugal.

Tel: +351218428215

E-mail: submissao@actamedicaportuguesa.com

www.actamedicaportuguesa.com

ISSN:0870-399X | e-ISSN: 1646-0758

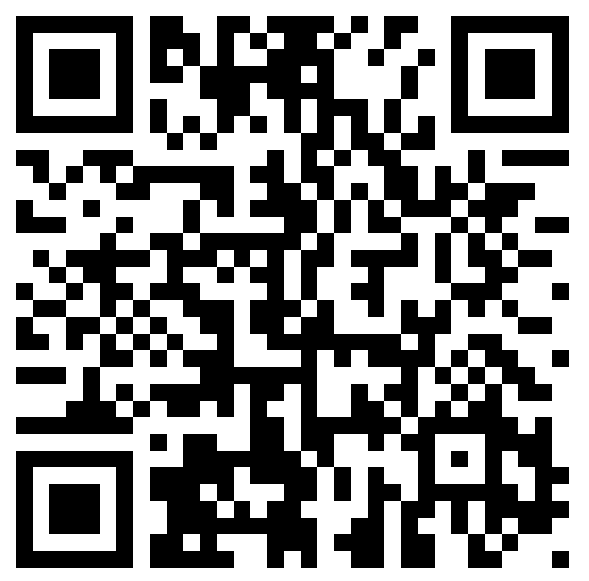

